\title{
Aplicação do Design Thinking para Educadores no Desenvolvimento de uma Solução Inovadora
}

\author{
Iverson Luís Pereira ${ }^{1}$, Ana Juriti Guimarães ${ }^{1}$, Josué Silva Nascimento ${ }^{1}$, Severino \\ José Costa Neto ${ }^{1}$, Ricardo André Cavalcante de Souza ${ }^{2}$ \\ ${ }^{1}$ Bacharelado em Ciência da Computação (BCC) - Universidade Federal Rural de \\ Pernambuco (UFRPE) - Recife/PE - Brasil
}

${ }^{2}$ Departamento de Estatística e Informática (DEINFO) - Universidade Federal Rural de Pernambuco (UFRPE) - Recife/PE - Brasil

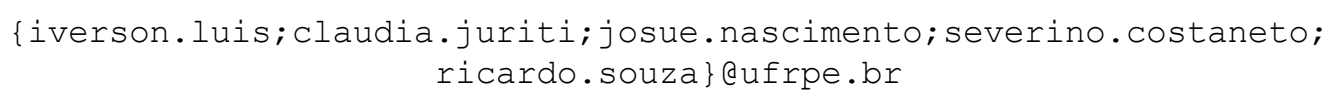

\begin{abstract}
This paper describes the experience of applying the Design Thinking for Educators approach in the development of an innovative software-based solution to solve an education-related problem. This approach helps to emerge and understand the key factors to guide the inception, design and construction of the solution. The proposed solution aims to improve the interaction between students and teachers during the class from a mechanism of real-time feedback of the contents taught and learned.
\end{abstract}

Resumo. Este artigo relata a experiência de aplicação da abordagem Design Thinking para Educadores no desenvolvimento de uma solução inovadora baseada em software para resolver um problema relacionado à educação. A abordagem experimentada auxilia a emersão e a compreensão dos fatoreschave para direcionar a concepção, design e construção da solução. A solução proposta visa melhorar a interação entre estudantes e professores durante as aulas a partir de um mecanismo de feedback em tempo real do conteúdo ensinado e aprendido.

\section{Introdução}

Com a popularização das tecnologias digitais, cada vez mais o processo de ensinoaprendizagem é apoiado por ambientes virtuais e ferramentas de software que permitem dinamizar a transmissão do conhecimento, bem como a interação entre professores e estudantes além dos encontros presenciais em sala de aula. Independentemente da modalidade de ensino, os estudantes e professores estão espacialmente separados na maior parte do tempo e, deste modo, a diversificação da comunicação entre eles dependerá da utilização correta das tecnologias disponíveis (SANTOS, 1999).

$\mathrm{Na}$ sala de aula, predomina ainda o método tradicional no qual o professor expõe o conteúdo e os estudantes apenas assistem passivamente (SAVIANI, 2008). Se, por um lado, a tecnologia pode dar suporte ao processo de ensino-aprendizagem mas que, por outro lado, ainda predomina o método tradicional de transmissão do conteúdo, a questão de pesquisa tratada neste trabalho consiste em como o professor pode ajustar e melhorar em tempo real o método de ensino a partir do feedback dos estudantes quanto ao conteúdo aprendido, e como melhorar a interação entre eles durante a aula e extraclasse. 
Este trabalho apresenta o relato de experiência da aplicação da abordagem de Design Thinking para Educadores (EDUCADIGITAL, 2014) para o desenvolvimento de uma solução baseada em software para o problema de pesquisa supracitado.

Entre os trabalhos correlatos, está o proposto por Silva et al. (2016) que consistiu no desenvolvimento de uma solução educacional, através de um processo baseado na abordagem Design Thinking, para gestão e recomendação de projetos multidisciplinares a partir dos perfis e habilidades de estudantes e professores. A diferenciação deste nosso trabalho está no escopo do problema e na análise de soluções correlatas.

Além desta seção introdutória, este artigo está estruturado em mais quatro seções. Na Seção 2, há uma breve explanação sobre o processo da abordagem Design Thinking para Educadores. Na Seção 3, há uma descrição da metodologia que orientou o desenvolvimento da solução educacional. Na Seção 4, são apresentados os resultados obtidos. Na Seção 5, são apresentadas as considerações finais.

\section{A Abordagem Design Thinking para Educadores}

A abordagem Design Thinking para Educadores prescreve o processo de Design para gerar e aprimorar soluções para desafios de diversos tipos, deixando uma liberdade para errar e aprender com os erros, gerando novas ideias, recebendo feedback de colaboradores e um reciclo de todo o processo (EDUCADIGITAL, 2014). Esta abordagem é baseada no Design Thinking (BROWN, 2010)

Quando as ideias surgem e estão relacionadas a um objetivo conhecido, podemos nomeá-la como insight, que se trata de percepções sintetizadas do aprendido na atividade realizada, permitindo uma nova visualização global e tornando-se um incentivador de novas ideias. A inovação é um processo complexo e não linear que pode ser explorado com a utilização do processo de Design. Na prática, esse procedimento é composto por fases que ajudam em seu desenvolvimento na imersão do processo desde a identificação do desafio até a construção da solução.

Para concepção e design da solução em atendimento ao desafio, são executadas cinco etapas de maneira não linear: Descoberta; Interpretação; Ideação; Experimentação e Evolução. Navegando por essas etapas, o primeiro passo seria identificar o problema específico e intencional a ser resolvido, gerando uma Descoberta, que irá construir uma base sólida para a ideia existente e uma melhor compreensão do estímulo, podendo daí ser feito uma Interpretação clara das percepções observadas. Dando continuidade ao processo, a etapa Ideação valoriza o pensamento expansivo, dando espaço para o surgimento de mais novas ideias, reaproveitando ou descartando possibilidades avaliadas, fazendo com que de maneira ocular e objetiva a etapa Experimentação chegue com um refinamento preciso de opções para continuidade da atividade proposta. Finalizando com a Evolução, esse procedimento leva ao planejamento do idealizado para que os colaboradores possam interferir com auxílio somativo, realizando à ação e documentação de todos o processo de construção do projeto.

Na próxima seção, são apresentadas as etapas do processo de Design executadas no contexto deste trabalho, exceto a Evolução que está fora do escopo deste trabalho, pois se trata de uma estágio de continuidade e melhoria da solução desenvolvida. 
VI Congresso Brasileiro de Informática na Educação (CBIE 2017)

Anais do XXIII Workshop de Informática na Escola (WIE 2017)

\section{Execução do Processo de Design}

O processo de Design foi executado desde a definição do desafio até a construção da solução proposta, a partir das seguintes etapas: Descoberta, para identificação do desafio para ser tratado; Interpretação, para estruturação de insights e oportunidades de inovação em resposta ao desafio de educação; Ideação, para geração de ideias de soluções inovadoras; e Experimentação, para implementação de um protótipo da solução para demonstração do valor a ser entregue e para obtenção de feedback junto aos usuários.

\subsection{Descoberta}

A primeira etapa consistiu na busca por um desafio relacionado à educação para ser trabalhado. O desafio pensado pelo time foi uma solução que pudesse ajudar a melhorar a interação entre estudantes e professores. No âmbito real, a interação com o professor é de certo modo feita por uma pequena parcela de estudantes em uma sala de aula.

$\mathrm{Na}$ Tabela 1, estão dispostos alguns problemas que impedem uma boa interação de estudantes e professores, e coisas que poderiam ser melhoradas em prol de uma boa relação entre os mesmos. Essa análise e síntese foi obtida por meio de discussões em grupo. Essas informações serviram como um gatilho de inspiração para elaboração de questionários e entrevistas junto aos interessados para possibilitar melhor compreensão do desafio definido.

Tabela 1. Análise e Síntese

\begin{tabular}{|l|l|}
\hline Coisas que poderiam ser melhores & \multicolumn{1}{c|}{ Como podemos? } \\
\hline - Horário em que o professor fica & - Como podemos estabelecer um \\
disponível na universidade & horário fixo ou flexível que atenda às \\
- Conteúdo aplicado nas aulas & necessidades dos alunos? \\
- Comunicação entre aluno e professor & Como podemos melhorar o conteúdo \\
- Despreparo do professor com o & das aulas ou mudá-los quando for \\
assunto abordado & necessário? \\
- Timidez do aluno em momentos de & Como podemos melhorar a \\
dúvidas ou pouco entendimento do & comunicação entre aluno e professor, \\
assunto & incluindo alunos introvertidos? \\
\hline
\end{tabular}

Com o intuito de aprender mais sobre o desafio, fomos em busca de ambientes e ferramentas que são comumente usadas no processo de ensino-aprendizagem, a fim de avaliar os fatores-chave que dão suporte à interação entre estudantes e professores. As ferramentas analisadas foram: Moodle, Correio Eletrônico e Edulify. Analisamos os seguintes fatores (1) preço; (2) suporte a produção de material didático; (3) suporte à realização de atividades extraclasse; (4) elaboração de questionários; (5) comunicação em sala de aula; (6) comunicação extraclasse; (7) e suporte à atividades durante a aula. O Gráfico 1 apresenta uma Matriz de Avaliação de Valor (KIM e MAUBORGNE, 2005) que descreve a curva de valor do mercado gerada pelo nível de atendimento médio (eixo vertical), pelas ferramentas analisadas, a cada um dos sete fatores-chave (eixo horizontal) identificados. Esse gráfico será comparado com a curva de valor da nossa solução, em etapa posterior do processo de Design. 


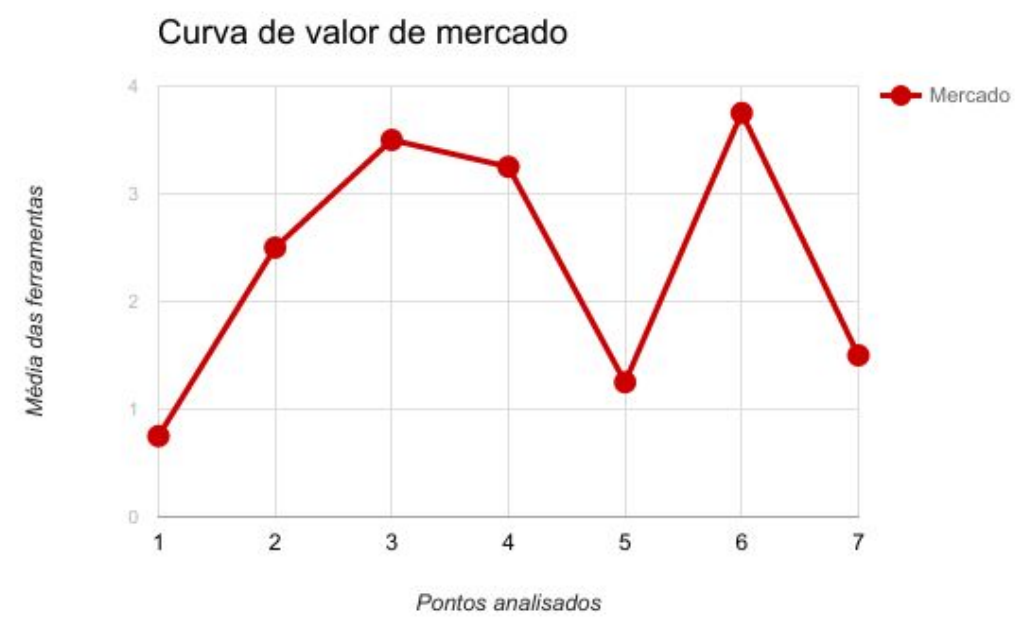

Gráfico 1. Curva de valor do mercado

A Curva de Valor permite avaliar quais pontos (fatores) podem ser melhorados e quais pontos podem ser inseridos como um diferencial, já que as outras ferramentas não o oferecem. Em seguida, imergimos no dia a dia de estudantes e professores com o intuito de detectar de fato a existência do problema da interação entre eles na sala de aula e fora dela. Foram realizadas visitas à escolas e entrevistas com o objetivo de levantar problemas, obter relatos e sugestões das próprias pessoas que vivenciam o ambiente educacional. A partir do feedback obtido, foi possível entender quais são os problemas que afetam a interação e quais são as boas práticas que fomentam trocas de ideias e conhecimento entre alunos e professores.

Operacionalmente, o primeiro passo foi listar ideias, restrições ou barreiras que poderiam ser o motivo de uma possível má relação acadêmica. Destas, podemos destacar: estudantes possuem perfis de aprendizagem diferentes, ou seja, cada um tem sua peculiaridade na forma de como absorve o conhecimento; trocas de professor durante o período letivo; e desentendimento prévio entre estudante e professor. Depois, levantamos coisas que já sabíamos: professores são resistentes a mudanças; estudantes ficam conectados à Internet durante as aulas; e uso de metodologias de ensino ultrapassadas. O segundo passo foi a realização de entrevistas com: pedagogos, que possuem conhecimento técnico na área educacional; equipe de um órgão responsável pela coordenação, supervisão e controle das atividades de ensino de graduação; coordenadores dos cursos de graduação; e estudantes de graduação. O objetivo foi aprender e obter informações que não conhecíamos, com a finalidade de nos inspirarmos a criar uma solução que ajudasse a solucionar o desafio.

\subsection{Interpretação}

Nessa segunda etapa foi realizada a análise dos dados obtidos na etapa de Descoberta, com o objetivo de coletar aprendizados, transformar histórias em insights valiosos, gerar temas e decifrar os achados relacionados ao desafio proposto. Observações, visitas em campo e conversas rendem ótimas inspirações para encontrar acepções e transformá-las em oportunidades de ação no processo. Fundamentados nisso, foram realizadas entrevistas com pessoas que não estavam ligadas diretamente ao ambiente onde o problema surgiu, a fim de entendermos o funcionamento da interação humana e social. 
Com o objetivo de ter um melhor entendimento sobre as histórias coletadas, notas, observações e impressões, fez-se necessário organizar as informações obtidas por meio das ferramentas visuais Mapa de Empatia e Mapa Conceitual (VIANNA et al., 2012). O primeiro é uma ferramenta de síntese das informações sobre os atores, numa perspectivas do que eles dizem, pensam e sentem sobre o problema, possibilitando uma melhor organização dos dados coletados de modo a facilitar o entendimento das situações, comportamentos e do problema no qual eles estão inseridos. O segundo permite organizar dados complexos obtidos durante a pesquisa de campo com o objetivo de ilustrar as conexões entre os dados, permitindo que novas informações possam ser extraídas. A evolução desses dados angariou levantamentos de possíveis temas no qual os elementos se encaixam.

Ao final da Interpretação, os principais insights obtidos foram: estudantes são reservados em sala de aula, mas gostam de ajuda acessível; professores desejam interações extraclasse com estudantes de maneira programada; necessidade de comunicação mais efetiva extraclasse; aulas dinâmicas para ajudar a instigar os estudantes; agendamento de encontros extraclasses que possam ajudar professores e estudantes; método de confirmação de presença em sala mais eficiente; auxílio aos estudantes que sentem timidez ao fazer perguntas ou serem questionados em sala; aulas cuidadosamente planejadas para facilitar uma transmissão do conteúdo de maneira mais eficiente; estudantes querem materiais de apoio em tempo real para uma possível consulta durante a aula. Esses insights referem-se basicamente a quatro momentos: pré-aula; interação estudante-professor na sala de aula; interação estudante-professor extraclasse; interação aluno-aluno.

\subsection{Ideação}

$\mathrm{Na}$ Ideação realizamos sessões de brainstorm $^{1}$ com o objetivo de gerar ideias para atender o desafio, agora melhor entendido após as etapas de Descoberta e Interpretação. Além disso, foi realizado um workshop com outras pessoas para avaliação das ideias geradas de modo a nos dar feedback a respeito das mesmas.

Individualmente, os membros do time definiram possíveis ideias de soluções que poderiam atender os insights. Em grupo, as ideias de soluções produzidas foram analisadas, complementadas e melhoradas. Para validar as ideias fizemos um workshop de cocriação com pessoas externas ao projeto. O workshop foi realizado em nossa instituição de ensino e contamos com a presença de estudantes e professores. Primeiramente houve uma explanação sobre o projeto, mostrando e explicando os artefatos já desenvolvidos para excitar a imaginação e a compreensão dos participantes. Em seguida, apresentamos nossas ideias, havendo assim momentos onde eles as questionaram e também puderam contribuir com melhorias das mesmas.

Ao final da Ideação, foi possível elaborar uma curva de valor da ideia de solução proposta que se mostrou mais promissora após o workshop de cocriação. O Gráfico 2 apresenta a curva de valor da solução proposta em relação à média das soluções correlatas (Mercado) avaliadas na etapa de Descoberta (Gráfico 1).

\footnotetext{
${ }^{1}$ Brainstorm é uma palavra em inglês, cujo significado em português é "tempestade mental", seu objetivo é a obtenção de ideias por um grupo de pessoas.
} 
É possível notar que a curva de valor da solução proposta (denominada PEdu) é diferenciada em relação ao mercado, principalmente pela inclusão de dois novos fatores: o primeiro possibilita feedback dos estudantes para o professor, durante a aula, quanto ao conteúdo ensinado e aprendido; o segundo, refere-se ao agendamento de tutoria extraclasse, no qual estudantes e professores poderão gerenciar encontros de caráter acadêmico.

\section{Curva de valor da Solução x Mercado}

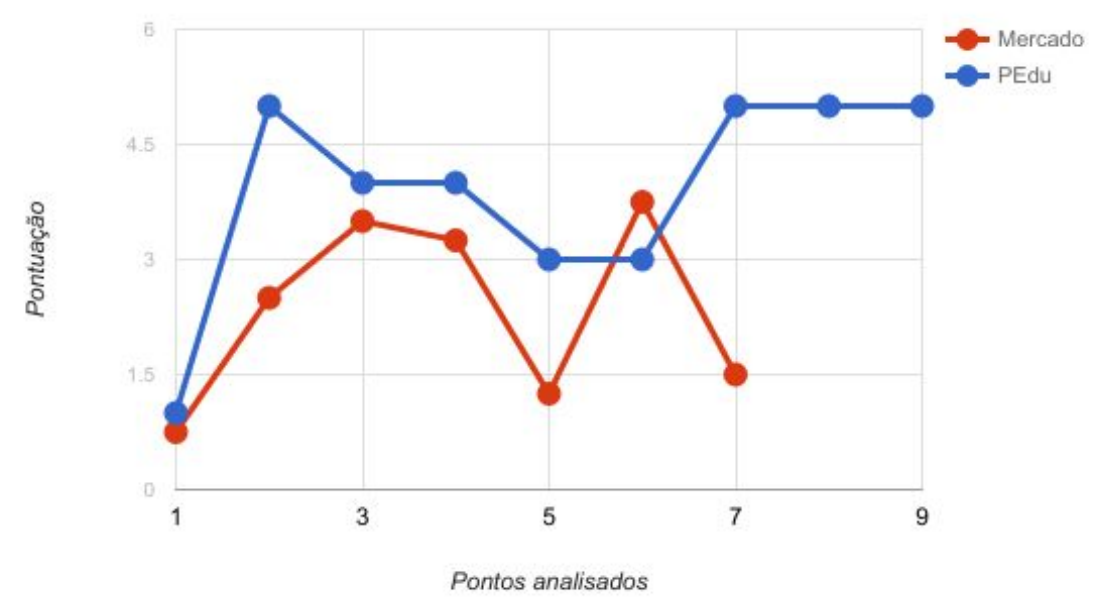

Gráfico 2. Comparativo entre a curva de valor da Solução x Mercado

\subsection{Experimentação}

$\mathrm{Na}$ etapa de experimentação materializamos a ideia de solução escolhida na Ideação de modo a ser avaliada pelas pessoas para obtenção de feedback. O primeiro passo foi realizar a criação de um storytelling ${ }^{2}$, através de uma animação que ilustra um possível cenário de uso da solução. Para construção do storytelling foi utilizada a ferramenta GoAnimate ${ }^{3}$.

A Figura 1 apresenta alguns quadrinhos com a síntese da storytelling que ilustra o cenário de feedback em tempo real sobre o andamento da aula, no qual há um professor ensinando, porém ele não sabe se os estudantes estão compreendendo o assunto. O professor então solicita que os estudantes realizem uma atividade em sala de aula através da ferramenta PEdu. O professor poderá agora consultar um gráfico informativo (dashboard) mostrando o desempenho e o nível de aprendizado individualizado dos estudantes. Dessa forma, o professor conseguirá acompanhar o andamento da turma ao longo da aula, o que poderá levá-lo a ajustar a didática ou mudar forma de explicar o conceito para um melhor desempenho de cada estudante. $\mathrm{O}$ storytelling produzido foi apresentado para estudantes e professores e o feedback obtido ajudou em melhorar alguns aspectos da solução proposta (PEdu). O storytelling está disponível para consulta no canal Youtube em $\underline{\text { https://youtu.be/HjcreecVRos. }}$

\footnotetext{
${ }^{2}$ Storytelling é uma palavra em inglês que está relacionada a uma narrativa e significa a capacidade de contar histórias.

${ }^{3}$ https://goanimate.com/, uma ferramenta para a construção de animações.
} 
VI Congresso Brasileiro de Informática na Educação (CBIE 2017)

Anais do XXIII Workshop de Informática na Escola (WIE 2017)

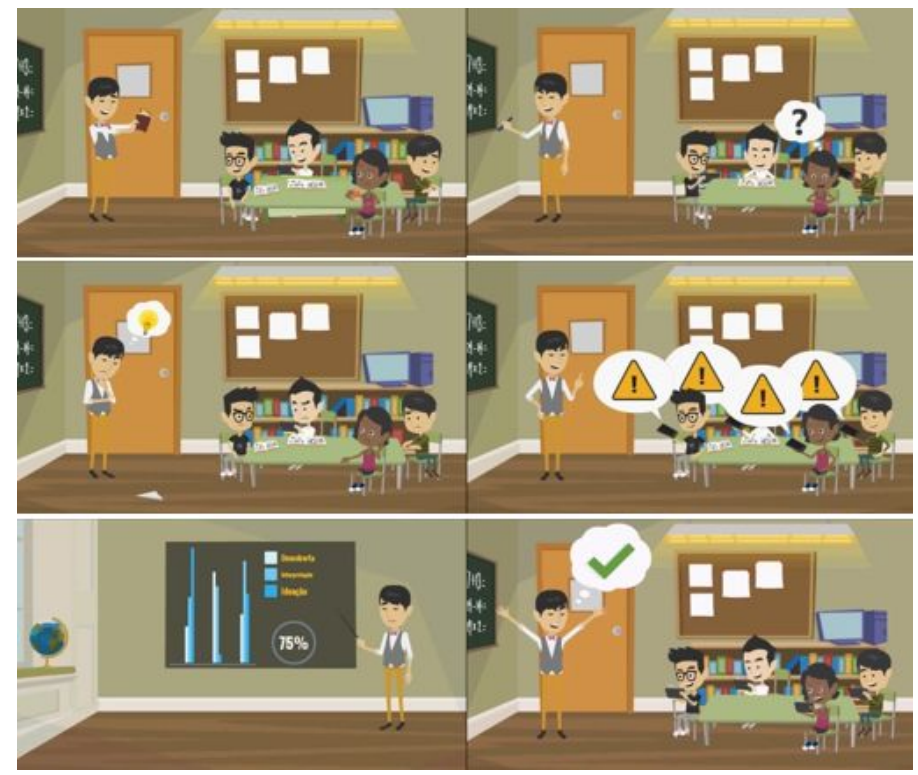

Figura 1. Quadrinho ilustrando o uso de feedback em tempo real durante a aula

Com a ideia de solução bem definida, chegou o momento de colocar a ideia de solução em ação através da prototipação. Inicialmente, reunimos todas as informações a respeito do projeto e durante algumas horas ficamos esboçando possíveis alternativas de como seria a interface com o usuário, qual o conteúdo e localização dos componentes. Esse processo foi fundamental para a construção do pensamento para a elaboração de uma possível aplicação funcional que oferecesse os recursos levantados na etapa de Ideação. Em seguida, definimos o framework de desenvolvimento. Decidimos pela implementação de um aplicativo para dispositivos móveis por meio da plataforma Ionic Framework ${ }^{4}$. O protótipo está mais detalhado na próxima seção.

O último passo da Experimentação foi a disponibilização do protótipo funcional para uso por estudantes e professores. Foram aplicados questionários online no qual pudemos obter feedback sobre a aplicação. Primeiramente, os estudantes e professores responderam a três perguntas sobre como eles enfrentam os problemas na sala de aula. Depois utilizaram o protótipo PEdu e responderam a mais três perguntas de como a ferramenta os estaria ajudando a mitigar os problemas de sala de aula. Como resultado, $55 \%$ dos respondentes afirmaram que a ferramenta PEdu ajudaria integralmente na melhoria da interação entre estudantes e professores, e para $45 \%$ ajudaria parcialmente.

\section{Resultados e Discussões}

A solução proposta neste trabalho possibilita feedback dos estudantes para o professor durante a aula, quanto ao conteúdo ensinado e aprendido, bem como um mecanismo de agendamento de tutoria extraclasse. O protótipo da solução foi testado e avaliado por estudantes e professores, e os resultados mostraram que a solução educacional baseada em software desenvolvida pode ser uma ferramenta para encorajar a participação ativa de estudantes introvertidos e permitir o professor acompanhar o nível de aprendizado dos estudantes durante a aula, além de ajudá-los a gerenciar encontros de tutoria.

\footnotetext{
${ }^{4}$ https://ionicframework.com/, é uma tecnologia para o desenvolvimento de aplicações móveis que pode ser disponibilizada para várias plataformas.
} 
A Figura 2 mostra telas do aplicativo PEdu na visão do estudante, à esquerda são mostrados os eventos e à direita as atividades da aula. O PEdu é estruturado em três módulos: (1) Pedu Line; (2) Agenda; e (3) Aula. O módulo PEdu Line consiste nos eventos de aula e tutoria, ou seja, é uma linha de tempo que mostra quais serão as próximas aulas e se há algum encontro de tutoria agendado. O módulo Agenda permite que o estudante agende dia e horário para um encontro de tutoria com professor de seu interesse. O módulo Aula permite ao aluno responder atividades passadas pelo professor durante a aula ou enviar dúvidas de forma anônima, fazendo com que estudantes introvertidos possam interagir com o professor. As telas do protótipo PEdu estão disponíveis para consulta em https://goo.gl/hwRWPi.

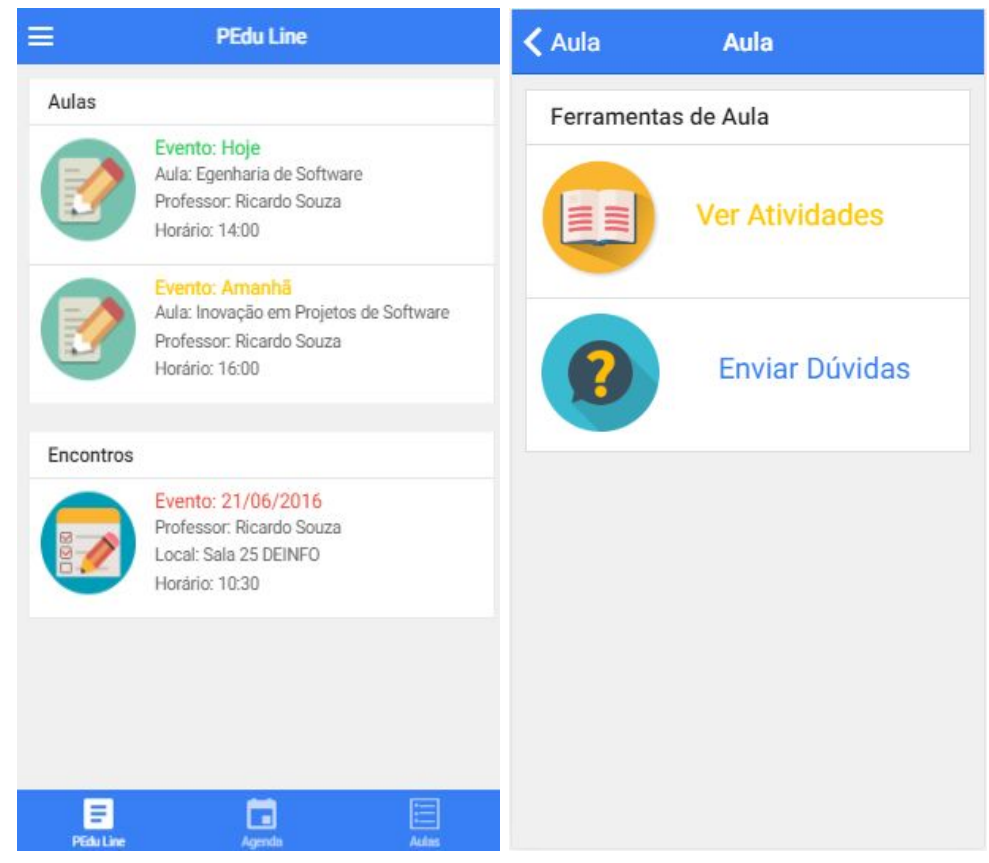

Figura 2. UI PEdu: lista de eventos à esquerda; opções da aula à direita

A Figura 3 apresenta a tela do protótipo PEdu na perspetiva do professor, na qual à esquerda é possível utilizar as ferramentas de aula: incluir uma nova atividade para ser respondida pelos estudantes; acompanhar o nível de aprendizado com base nas resposta dos estudantes; e tirar dúvidas postadas pelos estudantes. À direita da Figura 3 é apresentada uma ilustração do painel de controle (dashboard) que permite ao professor identificar os níveis de aprendizado por meio dos acertos e erros dos estudantes, bem como o nível de satisfação dos estudantes em relação a aula.

O processo de desenvolvimento de software, independente do paradigma ágil ou prescritivo, visa a entrega de funcionalidades para atender requisitos declarados pelos usuários. Este tipo de abordagem é eficaz quando as atividades a serem automatizadas estão bem estabelecidas. Quando o problema não está bem definido e precisa ser melhor compreendido antes de qualquer implementação, precisamos ir além do que os usuários falam e, também, observar como eles se comportam e se sentem em um determinado contexto. Para estes casos, a abordagem Design Thinking é apropriada, pois fornece um modelo de pensamento centrado no ser humano e colaborativo que leva à concepção de soluções a partir da imersão no contexto do problema, antes do design da solução. 
VI Congresso Brasileiro de Informática na Educação (CBIE 2017)

Anais do XXIII Workshop de Informática na Escola (WIE 2017)

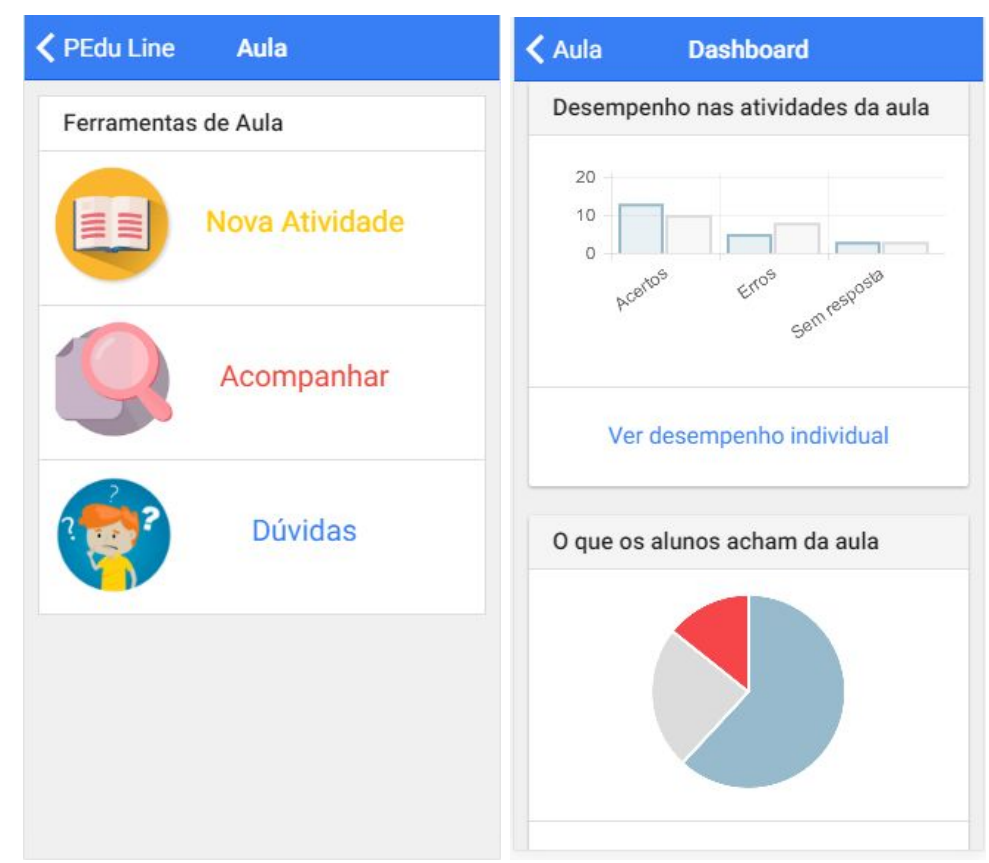

Figura 3. UI PEdu: ferramentas da aula à esquerda; dashboard à direita

O Design Thinking foi sistematizado para a área de educação através de uma iniciativa denominada Design Thinking for Educators (IDEO, 2012) que objetiva o desenvolvimento de soluções inovadoras para a sala de aula e para o processo de ensino-aprendizagem. A versão traduzida para o português do Brasil denominada Design Thinking para Educadores foi uma realização do Instituto Educadigital (EDUCADIGITAL, 2014) e procura ser "um meio para desenvolver o pensamento crítico e a capacidade de inovação dos estudantes e professores brasileiros".

A diferenciação deste trabalho foi a utilização do processo de design, prescrito pela abordagem Design Thinking para Educadores, para o desenvolvimento de uma solução baseada em software para mitigar o problema de como melhorar a experiência em sala de aula quanto ao método de ensino do professor a partir do feedback dos estudantes em tempo real sobre o conteúdo aprendido.

A experiência da execução do processo de design aplicado ao desenvolvimento de soluções baseadas em software mostrou-se bastante relevante e merece ser compartilhada para estimular outras iniciativas, em especial na área da educação. Além disso, do ponto de vista de formação humana, o processo de design fomentou na equipe executora (estudantes de graduação) habilidades exigidas pelos trabalhos centrados no conhecimento, tais como, trabalho em equipe, pensamento abdutivo, resolução criativa de problemas e entendimento aprofundado do problema antes da elaboração da solução.

\section{Conclusões e Trabalhos Futuros}

A interação ineficiente entre estudantes e professores pode acarretar em perdas consideráveis no processo de ensino-aprendizagem quando o feedback entre eles é ineficiente (COSTA et al., 2016). Para Silva (2012), a relação professor-estudante é uma forma de interação que dá sentido ao processo educativo, uma vez que é no coletivo que os sujeitos elaboram conhecimentos. 
VI Congresso Brasileiro de Informática na Educação (CBIE 2017)

Anais do XXIII Workshop de Informática na Escola (WIE 2017)

Neste contexto, o processo de Design nos ajudou a desenvolver uma proposta de solução para auxiliar estudantes e professores a obterem uma melhor interação no âmbito acadêmico. Por meio da experimentação do protótipo, professores e alunos avaliaram positivamente que a solução, denominada PEdu, pode contribuir para o processo de ensino-aprendizagem. Durante a execução das etapas, foram produzidos diversos artefatos com uma grande quantidade de informações que foram sendo lapidadas através de feedbacks e pesquisas. Essa sistemática permitiu a identificação de critérios relevantes centrados na perspectiva dos interessados que direcionaram o desenvolvimento da solução proposta. O PEdu oferece soluções para apoiar dificuldades na interação entre estudantes e professores, disponibilizando formas de iniciar e manter uma colaboração eficiente visando a aprendizagem pelos estudantes.

Como trabalho futuro o próximo passo será levar a ferramenta proposta para outras modalidades de ensino, desse modo será possível obter uma outra perspectiva sobre o quanto essa solução poderá contribuir para uma melhor interação entre alunos e professores de modo efetivo.

\section{Referências}

Brown, T. (2010). Design Thinking: uma metodologia poderosa para decretar o fim das velhas ideias. Rio de Janeiro, RJ: Elsevier.

Costa, E.; Fechine; J., Silva, P.; Rocha, H. (2016). Modelos de Feedback para Estudantes em Ambientes Virtuais de Aprendizagem. Anais da Jornada de Atualização em Informática na Educação (JAIE).

Educadigital, I. (2014). Kit de Design Thinking para Educadores. Disponível em http://www.dtparaeducadores.org.br/. Acessado em Junho de 2017.

IDEO (2012). Design Thinking for Educators, Version 2. Disponível em https://designthinkingforeducators.com/. Acessado em Maio de 2017.

Kim C.; Mauborgne, R. (2005). A Estratégia do Oceano Azul: como criar novos mercados e tornar a concorrência irrelevante. Rio de Janeiro, RJ: Elsevier.

Santos, N. (1999). Estado da Arte em Espaços Virtuais de Ensino e Aprendizagem. Laboratório de Engenharia de Software PUC-Rio COPPE/Sistemas/UFRJ.

Saviane, D. (2008). A pedagogia no Brasil: história e teoria. Campinas - SP.

Silva, A.; Correa, A.; Souza Filho, J.; Souza, R. (2016). Aplicação do Design Thinking em um Problema Educacional: Um Relato de Experiência. Anais do XXII Workshop de Informática na Escola (WIE 2016).

Silva, G. (2012). A Relação Professor-Aluno no Processo Ensino-Aprendizagem. Interdisciplinar: Revista Eletrônica da Univar no 8 vol. 3 p. 95 -100.

Vianna, M.; Vianna, Y.; Adler, I.; Lucena, B.; Russo, B. (2012). Design Thinking: inovação em negócios. Rio de Janeiro, RJ: MJV Press. 